\title{
BMJ Open Born to be Wise: a population registry data linkage protocol to assess the impact of modifiable early-life environmental exposures on the health and development of children
}

\author{
Matilda van den Bosch, ${ }^{1,2}$ Michael Brauer, ${ }^{1}$ Rick Burnett, ${ }^{3}$ Hugh W Davies, ${ }^{1}$ \\ Zoe Davis, ${ }^{1}$ Martin Guhn, ${ }^{1}$ Ingrid Jarvis, ${ }^{1}$ Lorien Nesbitt, ${ }^{1}$ Tim Oberlander, ${ }^{1}$ \\ Emily Rugel, ${ }^{1}$ Hind Sbihi, ${ }^{1}$ Jason G Su, ${ }^{4}$ Michael Jerrett ${ }^{5}$
}

To cite: van den Bosch M, Brauer M, Burnett R, et al. Born to be Wise: a population registry data linkage protocol to assess the impact of modifiable earlylife environmental exposures on the health and development of children. BMJ Open 2018;8:e026954. doi:10.1136/ bmjopen-2018-026954

- Prepublication history for this paper is available online. To view these files, please visit the journal online (http://dx.doi. org/10.1136/bmjopen-2018026954).

Received 28 September 2018 Revised 22 0ctober 2018 Accepted 24 October 2018

Check for updates

(C) Author(s) (or their employer(s)) 2018. Re-use permitted under CC BY-NC. No commercial re-use. See rights and permissions. Published by BMJ.

For numbered affiliations see end of article.

Correspondence to Dr Matilda van den Bosch; matilda.vandenbosch@ubc.ca

\section{ABSTRACT}

Introduction Deficiencies in childhood development is a major global issue and inequalities are large. The influence of environmental exposures on childhood development is currently insufficiently explored. This project will analyse the impact of various modifiable early life environmental exposures on different dimensions of childhood development.

Methods Born to be Wise will study a Canadian cohort of approximately 34000 children who have completed an early development test at the age of 5 . Land use regression models of air pollution and spatially defined noise models will be linked to geocoded data on early development to analyse any harmful effects of these exposures. The potentially beneficial effect on early development of early life exposure to natural environments, as measured by fine-grained remote sensing data and various land use indexes, will also be explored. The project will use data linkages and analyse overall and age-specific impact, including variability depending on cumulative exposure by assigning timeweighted exposure estimates and by studying subsamples who have changed residence and exposure. Potentially moderating effects of natural environments on air pollution or noise exposures will be studied by mediation analyses. A matched case-control design will be applied to study moderating effects of natural environments on the association between low socioeconomic status and early development. The main statistical approach will be mixed effects models, applying a specific software to dea with multilevel random effects of nested data. Extensive confounding control will be achieved by including data on a range of detailed health and sociodemographic variables.

Ethics and dissemination The study protocol has been ethically approved by the Behavioural Research Ethics Board at the University of British Columbia. The findings will be published in peer-reviewed journals and presented at scholarly conferences. Through stakeholder engagement, the results will also reach policy and a broader audience.

\section{Strengths and limitations of this study}

- Born to be Wise will analyse the impact of early-life environmental exposures, including during pregnancy, on childhood development by using a holistic measure of children's early social, emotional, cognitive and physical development.

- By using geocoded and linkable health registry data, a large number of covariates for both children and mothers will be included in the analyses.

- By focusing on modifiable environmental exposures, results from the project could inform policies aiming for healthier childhood environments with impact throughout the life course.

- Born to be Wise will use spatially varying environmental exposure data - on air pollution, noise and natural environments-to assess the joint and individual impacts on dimensions of childhood development, which can facilitate the generation of hypotheses for future investigation.

- The project only has access to developmental outcome data at one point in time, which raises issues of reverse causation and self-selection bias, but this will be addressed by subanalyses of individuals with changes in exposure over the study period, as well as by sibling analyses and a case-control study approach with matched subsamples of children with similar socioeconomic status but differing environmental exposures.

\section{INTRODUCTION}

Early childhood development is a strong predictor of health, well-being and social ability across the life course. ${ }^{1}$ Early development includes aspects of physical health and well-being, social competence, emotional maturity, language and cognitive development and communication skills. Two series in The Lancet $\left(2007^{2}\right.$ and $\left.2011^{3}\right)$ concluded that, globally, more than 200 million children 
under the age of 5 fail to reach their developmental potential. In Canada, where this project is located, approximately one in four children is considered 'vulnerable' to deficiencies in early development prior to entering Grade $1,{ }^{4}$ indicating that the child may not yet have developed the skills required to gain full benefit from school education. Vulnerability rates vary significantly within and between Canadian regions and can range from $10 \%$ to $60 \%$ between different neighbourhoods in a single city. ${ }^{5}$ These discrepancies correlate with inequalities in environmental and socioeconomic conditions, with an increased risk of vulnerability among children in socioeconomically disadvantaged environments. ${ }^{6}$ Between 2000 and 2010 , overall vulnerability rose by almost $30 \%$ in British Columbia, ${ }^{7}$ driven by worsening trends in the social and emotional domains. Studying the impact of multiple exposures in early life is critical to identifying predictors for the increased prevalence and unequal distribution of neurodevelopmental outcomes. Earlier studies suggest that family risk factors, which are strongly related to socioeconomic status (SES), are significant predictors of early developmental vulnerabilities, ${ }^{8}$ but neurotoxic agents and environmental pollution have been suggested to play important roles as well. ${ }^{9-13}$ Typically, previous work has rarely included physical (natural or built) environmental exposures in their analyses, and the potential impact of these factors has been insufficiently investigated despite their potential to affect large segments of the population given their ubiquity.

\section{Environmental exposures and childhood development}

Over the past few decades, the rate of urbanisation has increased in Canada and elsewhere, ${ }^{14}$ and access to natural environments (NE) - a potential health-promoting element of urban settings-is becoming increasingly threatened and unequally distributed. ${ }^{15-18}$ The changing environments and lifestyles of childrenincreased indoor screen time, sedentary behaviours, less outdoor play and reduced interactions with nature-have been the focus of recent scientific and policy analyses. ${ }^{19-21}$ The full implications of these broad changes for children's health and development remain unexplored, but preliminary studies indicate that excessive screen time may contribute to attention problems and school difficulties, while time spent outdoors, on the other hand, may improve emotional skills and support learning. ${ }^{22-24}$

Harmful environmental exposures, such as noise and traffic-related air pollution (TRAP), during sensitive developmental periods in early life, including in utero, may also lead to impairments in brain function, with potentially adverse consequences on early development ${ }^{25-33}$ and downstream effects on educational attainment and mental health. ${ }^{34-37}$ Prenatal exposure to TRAP has been associated with adverse effects on birth outcomes ${ }^{38} 39$ and childhood health and cognitive development. ${ }^{1040}$ Recent research also suggests that prenatal noise exposure may have a negative impact on birth outcomes ${ }^{41}{ }^{42}$ especially in combination with TRAP. ${ }^{43}$

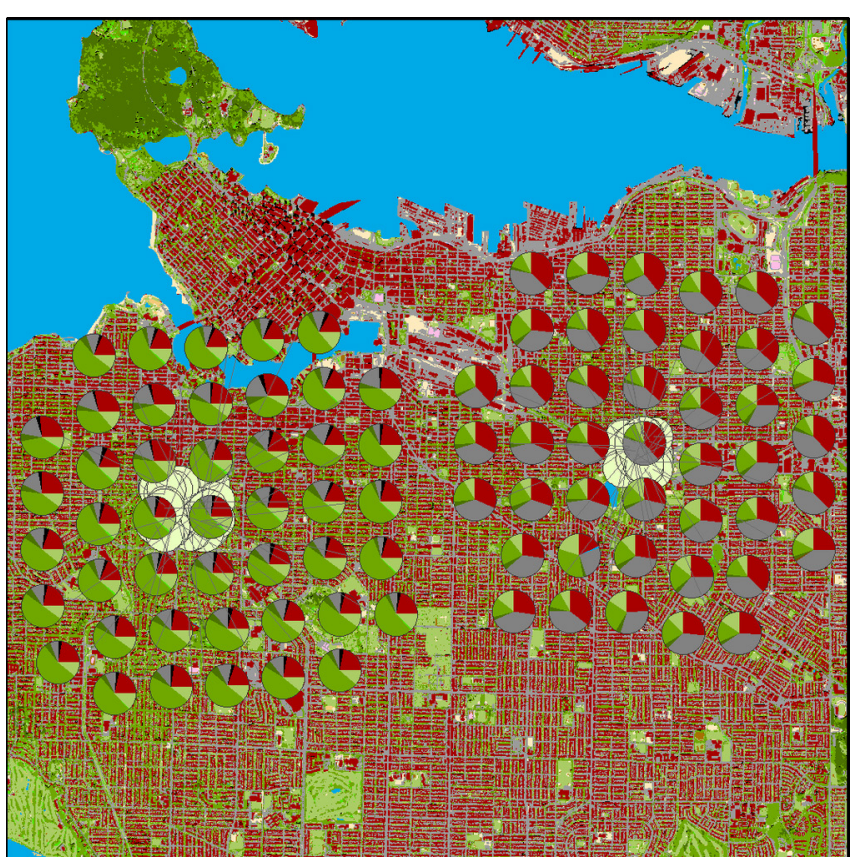

Figure 1 Postal code areas and land cover types in Metro Vancouver (Sources: Statistics Canada 2015, ${ }^{118}$ Metro Vancouver $2017^{119}$ ). Two example areas of 50 postal codes in Vancouver west and east, respectively, demonstrate difference in proportions of land cover. The west side of the region has, on average, a higher representation, within a buffer zone of $250 \mathrm{~m}$, of green (colour green in circles) than built (red) or paved (grey) areas compared with the east side.

Socioeconomically disadvantaged neighbourhoods often contain more harmful exposures and less NE, ${ }^{44-48}$ putting children growing up in these areas at higher health risks. Recent studies indicate that exposure to $\mathrm{NE}$ has a positive impact on early childhood health and development, including improved attention and cognitive capacity ${ }^{13} 244950$ and fewer symptoms of attention deficit hyperactivity disorder. ${ }^{51-56}$ These associations may be due in part to moderating effects of NE on TRAP, ${ }^{57-61}$ heat ${ }^{62-64}$ and noise ${ }^{65-67}$; thus, a positive effect of NE would be mediated by a reduction of those harmful factors. NE may also influence early childhood development through several other pathways, including: (1) providing areas for physical activity and active play ${ }^{68-70} ;$ (2) reduced stress among both parents and children ${ }^{71-73}$; (3) improved affect, cognition and mental health ${ }^{74-77}$; (4) improved social capital and positive psychosocial influences ${ }^{78-81}$; (5) improved immune system development by exposure to microbial diversity ${ }^{82-84}$; and (6) mitigation of adverse developmental outcomes related to low SES, as previous studies suggest that SES-related health inequalities are smaller in green areas. ${ }^{8586}$

\section{Preliminary data}

Preliminary analyses suggest that socioeconomically disadvantaged areas of Metro Vancouver have a higher proportion of built and paved spaces, while more prosperous areas have more vegetation (figure 1). This indicates that 


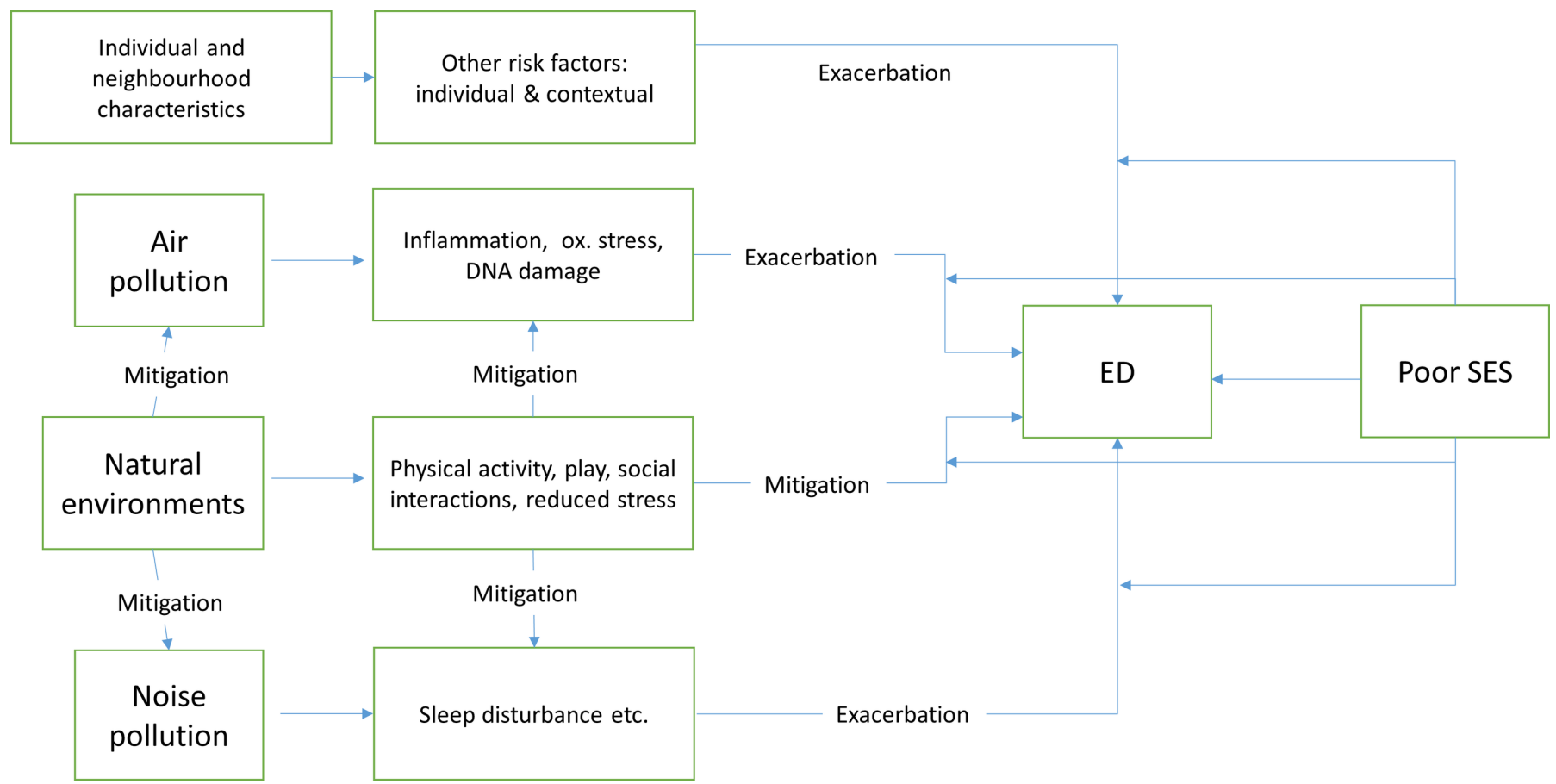

Figure 2 Exposure to natural environments (NE) in the neighbourhood reduces the negative impacts of air and noise pollution on early development (ED). NE exposure may also reduce inequalities associated with low socioeconomic status (SES), at least partly due to the mitigating impact on air and noise pollution. The combined effects of reduced risk factors and increased health-promoting behaviours (eg, physical activity, stress relief, social interactions) result in improved early development among children exposed to high levels of NE in early life.

there is a gradient in environmental exposures, but the impact on early development remains to be investigated.

\section{AIMS OF BORN TO BE WISE}

This project will investigate the following specific aims to determine whether:

Aim 1: exposure to NE is positively associated with early childhood development and health;

Aim 2: exposure to TRAP and noise are negatively associated with early childhood development;

Aim 3: areas of high NE are associated with reduced negative effects of TRAP or noise exposures on early development; and

Aim 4: exposure to NE moderates the effect of poor SES on early childhood development.

See figure 2 for a conceptual model of the suggested pathways and moderators.

\section{Methods and analysis}

Born to be Wise is based on individual-level data linkage and analysis of existing population-based data held by Population Data BC (PopData BC, https://www.popdata. bc.ca/), including person-specific data on early development and demographic, health and socioeconomic variables. Individual estimates of exposure are based on existing models, maps and remote sensing products, all of which are linked to the population data with high spatial resolution.
To address the aims, the project will link indicators of multiple domains of early development to data on: (1) exposures to TRAP, noise and NE in the residential environment (time-weighted based on residential address history); (2) SES of children's neighbourhoods; and (3) covariates, such as maternal and child health status. Participant data are geocoded at the six-digit postal code of the residential address, which corresponds to the centroid of one block face or an apartment building in the study area, and all linkages, apart from SES, will occur at this spatial level.

\section{Study area}

Metro Vancouver.

\section{Key study variable, primary outcome and cohort}

The project will draw on a province-wide population-level data set on children's early development, the Early Development Instrument (EDI). ${ }^{87}$ The EDI measures children's readiness to learn at school across five domains (see table 1): (1) physical health and well-being; (2) social competence; (3) emotional maturity; (d) language and cognitive development; and (e) communication skills and general knowledge. The five domains are all predictors of later achievement in school-individually and as a composite score. ${ }^{88}$ The instrument demonstrates good psychometric properties, ${ }^{90-92}$ including reliability across different groups of children. ${ }^{91}{ }^{93}$ The EDI database represents the only population-based database 


\begin{tabular}{|c|c|}
\hline EDI domain & EDI subdomain \\
\hline $\begin{array}{l}\text { Physical health and } \\
\text { well-being }\end{array}$ & $\begin{array}{l}\text { Physical readiness for school } \\
\text { Physical independence } \\
\text { Gross and fine motor skills }\end{array}$ \\
\hline Social competence & $\begin{array}{l}\text { Overall social competence } \\
\text { Responsibility and respect } \\
\text { Approaches to learning } \\
\text { Readiness to explore new things }\end{array}$ \\
\hline Emotional maturity & $\begin{array}{l}\text { Prosocial and helping behaviour } \\
\text { Anxious and fearful behaviour } \\
\text { Aggressive behaviour } \\
\text { Hyperactivity and inattention }\end{array}$ \\
\hline $\begin{array}{l}\text { Language } \\
\text { and cognitive } \\
\text { development }\end{array}$ & $\begin{array}{l}\text { Basic literacy } \\
\text { Interest in literacy/numeracy, and } \\
\text { uses memory } \\
\text { Advanced literacy } \\
\text { Basic numeracy }\end{array}$ \\
\hline $\begin{array}{l}\text { Communication } \\
\text { skills and general } \\
\text { knowledge }\end{array}$ & $\begin{array}{l}\text { Communicates easily and effectively } \\
\text { Participates in storytelling } \\
\text { Articulates clearly } \\
\text { Shows adequate knowledge } \\
\text { Uses native language proficiently }\end{array}$ \\
\hline
\end{tabular}

Each is scored on a scale of 0 to 10 . If a child falls in the bottom 10th percentile, he or she is considered 'vulnerable' in that domain. An 'overall vulnerability' flag is set if a child is vulnerable in one or more domains.

on early childhood development in British Columbia and numerous other jurisdictions in Canada. ${ }^{5}$

Since 1999, the EDI has been administered in kindergarten classrooms throughout Metro Vancouver to children at age 5. For the Born to be Wise Project, EDI data for 34402 children from 2005 to 2010 (corresponding to birth cohorts 2000-2005) are linkable to exposure data and will provide a population-based and representative cohort.

Born to be Wise will follow standard approaches for operationalising vulnerability via EDI scores. For logistic regression analyses, children are classified as being 'vulnerable' in a given EDI domain, using a 10th percentile cut-off score based on a normative Canadian data set of children. ${ }^{94}$ Children with at least one EDI domain score in the bottom 10th percentile are categorised as 'vulnerable in at least one developmental domain'. ${ }^{87}$ For linear regression analyses, continuous EDI scores, ranging from 0 to 10 for each domain and from 0 to 50 for the overall EDI score, will be used.

\section{Individual children and parental covariates}

Multiple child-level and parent-level variables that have been found to be predictors of early development ${ }^{8}(\mathrm{eg}$, maternal health, medication use and hospital records for mother and child) will be acquired from person-specific administrative British Columbia data sets, and aggregate-level socioeconomic and demographic variables (eg, median income, high school graduation rates, lone parent family rate and employment rates) will be drawn from Statistics Canada.

\section{Environmental exposures and variables \\ Natural environments}

In this project, NE will be defined as green and blue spaces. Most of the earlier research using remote sensing for estimating natural environments has used the Normalised Difference Vegetation Index (NDVI) with $30 \mathrm{~m}$ resolution from Landsat images. At this relatively coarse resolution, however, it can be difficult to interpret objects, because the minimum spatial unit (pixel) may not be homogenous. This mixed pixel problem ${ }^{95}$ may result in misclassification of exposure to NE. This project will therefore take advantage of high resolution data from Planet $(3 \mathrm{~m})$, WorldView2 $(2 \mathrm{~m})$ and NASA imagery $(0.5 \mathrm{~m})$, to minimise errors in exposure estimates. These higher-resolution images will yield highly detailed estimates of NE exposure over the entire study area. Images will be radiometrically corrected and presented in pixel values (digital numbers) that will be converted to the Top of Atmosphere (TOA) radiance through established algorithms. The NDVI will be derived to represent the degree of vegetation or water at a location. The NDVI is calculated as ${ }^{96}:$ NDVI $=($ NIR - VIS $) /($ NIR + VIS $)$ where VIS and NIR stand for the spectral reflectance measurements acquired in the visible (ie, red band) and near-infrared regions, respectively. NDVI ranges between -1 and 1 with higher numbers indicating more green vegetation. Freestanding water, such as oceans, lakes and rivers, usually has very low NDVI values, so hydrography data from Natural Resources Canada will also be used to classify water bodies. NDVI values will be assigned to study participants through a raster overlay to their residential location and through a series of network buffers with radii of $50 \mathrm{~m}, 100 \mathrm{~m}, 200 \mathrm{~m}, 300 \mathrm{~m}, 400 \mathrm{~m}, 500 \mathrm{~m}$ and $1 \mathrm{~km}$. While it is often assumed in urban planning that approximately $300 \mathrm{~m}$ represents a 'healthy' maximum distance to $\mathrm{NE}$, there is no scientific consensus ${ }^{97}$ and the project will therefore test for different distances, assuming potentially different health pathways depending on buffer size (eg, larger buffers for physical activity and smaller buffers for immediate stress recovery). Using residential locations, average exposure will be calculated across the full period by calculating precise time-weighted personal exposure estimates (at the defined time windows - prenatally, at birth and at 1, 3 and 5 years of age).

A limitation of remotely sensed metrics is that different types or qualities of NE cannot be sufficiently identified, obscuring potential differences in effect depending on the type of NE exposure. We will address this issue by adding three recently described NE metrics, specifically developed for Metro Vancouver: a categorised land cover map, a Natural Space Index (NSI) and a streetlevel Green View Index (GVI). The land cover map was developed from RapidEye satellite imagery and LiDAR data sets that were combined and processed to produce a high-resolution $(5 \mathrm{~m})$ land cover map of Metro 
Vancouver. It includes 14 different land cover categories, distinguishing between deciduous and coniferous trees, grass, shrubs and herbs, among other classifications. ${ }^{98}$ The NSI integrates assessments of presence (assessed from NDVI values), form (extracted from municipal and private databases), access (evaluation of restrictions such as private ownership) and quality (appraised by using the Public Open Space Desktop Appraisal Tool ${ }^{99}$ ) of NE. ${ }^{100}$ The GVI was developed by using panoramic images from Google Street View, ${ }^{101}$ creating an urban greenery assessment tool that captures human perceptions of NE from the street, ${ }^{102}$ which might represent the influence of $\mathrm{NE}$ views from outside the home.

1. Traffic related air pollution: Residential TRAP exposure will be quantified using high-resolution land use regression (LUR) models for nitrogen dioxide $\left(\mathrm{NO}_{2}\right)$ and particulate black carbon (BC). Specific $\mathrm{NO}_{2}$ and BC LUR models are available for Metro Vancouver. These models combine detailed monitoring of TRAP in various locations and geospatial predictor variables that define land uses related to TRAP sources and geographic determinants around the sampling locations. The models have been used previously to examine associations with birth outcomes. ${ }^{38}{ }^{43}$ LUR models are also available for fine particle mass concentrations $(\leq 2.5 \mu \mathrm{m})$ and for ultrafine particles $(\leq 0.1 \mu \mathrm{m}) .{ }^{103} 104$ Traffic proximity measures will also be derived.

2. Noise: Born to be Wise will estimate noise exposure levels using multiple metrics, all in A-weighted decibels: (1) annual average 24 hours noise levels (Lden,A), which integrates noise levels during the day, evening and night, with $5 \mathrm{~dB}(\mathrm{~A})$ weighting added to evening noise and $10 \mathrm{~dB}(\mathrm{~A})$ weighting added to night noise to reflect increased sensitivity to noise during these periods; (2) daytime exposure (Lday,A); and (3) night-time exposure (Lnight,A). The project will apply a previously developed predictive model ${ }^{105}$ that uses noise prediction software (Computer Aided Noise Abatement; Datakustik, Greifenberg, Germany) to estimate annual average community noise levels during the study period. ${ }^{105}$ The noise exposure data include road type, intersection locations, traffic speed and volume, railway data, aircraft data (noise forecasts produced by Vancouver International Airport Authority), topography and building heights and footprints. The annual A-weighted equivalent continuous noise level will be calculated for a $10 \times 10 \mathrm{~m}$ grid that will then be averaged for each postal code area.

\section{Linkage of data and temporal variation}

Through the British Columbia Perinatal Data Registry, mothers will be linked to their children, with prenatal geocodes based on each mother's residential address. Individuals living in the same household can also be identified by this method, making it possible to link siblings to each other and to their residential location. Environmental exposures will be linked to participants through their six-digit residential postal codes, using the average of all $10 \times 10 \mathrm{~m}$ grid values within postal code boundaries (noise) and postal code centroids (TRAP and NE). Because the study region is highly urbanised, the majority of postal codes represent small geographic areas, comprising about 35 residents for a typical cohort. Based on results from previous studies, the spatial patterns of environmental exposures are assumed to be highly correlated over time. ${ }^{106}$ Thus, the project will use existing models and extrapolate, both backcasting and forecasting, in accordance with previously applied methods, ${ }^{106}$ to predict exposures for different time periods. Earlier studies suggest that residential mobility is high during children's first 5-7 years (up to 30\%), ${ }^{107} 108$ which will provide opportunities for assessing variation in environmental exposures. The linked data allow for residential history assignment through coding of participants' residence locations, and for distinguishing exposures at various time windows.

\section{Statistical design and analysis strategy}

In modelling the effects of environmental exposures, Born to be Wise will treat EDI outcome data both dichotomously and continuously. Apart from area-level SES, all covariates will be defined at an individual level. When considering the impact of contextual neighbourhood variables, the project will apply multilevel mixed models with two levels: level 1 is the individual level and level 2 represents the area level. Standard multilevel mixed models assume independence between clusters at a hierarchy level. The project will apply the multilevel Geographic and Multilevel Models for Environmental Public Health Indicators and Tracking (GAMEPHIT) software $^{109-111}$ to deal with potential spatial autocorrelation in residual variation that is not accounted for by fixed predictors in the model. This software works with both continuous and dichotomous outcomes. Stratified gender analyses will be conducted to assess whether gender differences exist in effect estimates. The project will include the following statistical analyses:

1. Mixed effects models to identify the independent effects of TRAP, noise and NE on early development

The project will first investigate the independent effects of TRAP on EDI with the following equation (eq. 1):

$$
Y_{s}=\beta_{0}+\beta_{1} C_{s}+\beta_{2} P_{s}+\beta_{3} N_{s}+\theta_{a}+\varepsilon_{s}
$$

$Y_{s}$ and $C_{s}$ are, respectively, the EDI score (continuous or dichotomous and summary score or separate domain) and TRAP exposure for child $s . \beta_{0}$ is the model constant. $\beta_{1}$ is the coefficient for TRAP exposure. $\beta_{2}$ is a vector of coefficients for the individual characteristics. $\beta_{3}$ is a vector of coefficients for possible neighbourhood confounding factors. $P$, represents the individual characteristics of child $s$, such as age, sex and race/ethnicity. $N_{s}$ represents neighbourhood confounding or modifying factors that might impact the relationship. $\theta_{a}$ is the random effect of neighbourhood census tract $a$ to account for non-independence of children living in the same area and $\varepsilon_{s}$ is the error term of child $s$. The project will investigate the 
association in eq. 1 assuming spatial dependency between level 2 neighbourhoods using the random effects model $(\text { GAMEPHIT })^{111}$. It is assumed that each neighbourhood has a spatial dependency in EDI outcome to its immediate neighbourhood (i.e., queen's adjacency).

Second, the project will investigate the independent effects of noise on EDI. The relationship is similar to eq. 1 with $Y_{s}$ and $C_{s}$, being, respectively, the EDI score and 24-hour, day, night or peak hour noise levels at home address of child $s$. Other variables have the same definition as in eq. 1 .

Third, the project will estimate the independent effects of NE on EDI. We will estimate NE measures for different buffer distances around residential addresses. These measures will be used separately to model their possible positive impacts on early child development. The relationship is similar to eq. 1 , with $Y_{s}$ and $C_{s}$, being, respectively, the EDI scores and NE measures at the residential address of child s. Similar to eq. 1, the associations between NE and EDI will be adjusted for confounding or cluster dependency.

For the above models, Born to be Wise will apply timeweighted average exposures from the prenatal period to the age of EDI assessment to identify the overall impact and changes. The project will also investigate age-specific impacts and critical exposure windows for effects on EDI. Subanalyses of children who have changed residences and associated exposures during the study period will be conducted to enable assessment of whether the length of exposures has an impact on outcomes. For example, it will be possible to define groups of children who have: (1) always had low exposure to NE (or other environmental exposures); (2) moved from low to high exposure; (3) moved from high to low exposure; or (4) always had high exposure. This will also enable identification of whether a certain time window has a stronger impact than another. ${ }^{112}$

Sensitivity analyses on siblings will be conducted to allow for identifying differences in exposure in the same family. Due to differences in age, residential moves may create variation in cumulative exposure (eg, an older sibling who moves at age 4 and a younger one at age 3 would have different time-weighted average exposures). These sensitivity analyses reduce the risk that self-selection bias affects the results by using the mobility data with the SES factor kept constant.

2.Mixed effects models to identify the moderation effects of NE on associations of TRAP or noise with early development:

Moderation effects of NE on associations of EDI with: (1) TRAP, (2) noise and (3) TRAP and noise combined will be identified by using a formal moderation model, thus assessing if a positive effect of NE on EDI might be mediated by a reduction in TRAP, noise or both. The statistical analysis method proposed by Preacher and Hayes $^{113}$ will be used to test the hypothesised moderation effects. This method allows for testing the statistical significance of the moderation effect, while adjusting for
Table 2 Pair matched case-control analysis

Case (High EDI

vulnerability)

\begin{tabular}{llll} 
& & High & Low \\
\cline { 3 - 4 } Control (low EDI vulnerability) & High & a & b \\
& Low & $c$ & d
\end{tabular}

EDI, Early Development Instrument; NE, natural

environments.

confounding or neighbourhood dependency. ${ }^{114} 115$ To identify a moderation effect of NE on combined TRAP and noise effects on EDI, the additive or multiplicative effects will be analysed, and a formative variable (addition or multiplication of the TRAP and noise values) will be created to summarise the total effect.

The project will also include causal analyses on the impact of NE on EDI among children of low SES, using a pair-matched case-control study design (see table 2). To do this, children of low SES will be matched by age, sex, TRAP and noise levels. Pairs of controls with high NE will be calculated and cased with low NE $(b)$, and pairs of controls with low NE will be cased with high NE $(c) ; b / c$ is the OR of impact of NE on EDI.

\section{Power calculations}

Previous research suggests that TRAP has an effect size of $11 \%-22 \%$ on cognitive development outcomes ${ }^{26}$ and noise has been linked to half an SD in this outcome. ${ }^{32}$ In earlier analyses, ${ }^{94}{ }^{116}$ effects from neighbourhood income in the range of 0.1 were observed on EDI, which has a mean of 7.4 and an SD of 2.6. This is much smaller than the observed effects of other environmental variables, but this smaller effect size was used to be conservative in power calculations. Calculations were based on a one-sided alternative hypothesis ('greater than') and desired power of 0.90 . A continuous outcome was assumed and alpha $=0.01$, which yielded a sample size of 1296 subjects, well below the projected study sample size.

The potential for detecting the moderation effect of NE on TRAP or noise was also calculated. The moderation effect is the indirect effect of product of two standard coefficients: (1) slope of air pollution/noise $\left(\beta_{21}\right)$ in association with the moderator $\mathrm{NE}$ and (2) slope of $\mathrm{NE}$ $\left(\beta_{32}\right)$ in impacts of NE and TRAP/noise with outcome EDI. Using the same small effect size and a conservative estimate of the effects of NE on air pollution demonstrated in other studies with a power of 0.9 and alpha $0.05,5133$ subjects are required. Power calculations were computed in $\mathrm{R}$ using the 'pwr.r.test' function in the 'pwr' package (https://cran.r-project.org/package=pwr) and in MedPower (https://davidakenny.shinyapps.io/ MedPower/2.

\section{Patient and public involvement}

Neither patients nor the public were involved in the development of this protocol. 


\section{ETHICS AND DISSEMINATION}

Born to be Wise conforms to Canada's TriCouncil Policy and UBC's 'Policy on Research and Other Studies Involving Human Subjects'. The project has been ethically approved. The project is considered minimal risk due to the anonymised nature of the data. All data will be securely stored and managed by PopData BC.

The findings from Born to be Wise will be communicated through international peer-reviewed scientific journals and through popular-scientific and policy channels. The project has broad connections and collaborations with numerous knowledge translation partners and provincial stakeholders, including regional health authorities and alliances for healthy living and healthy families. Meetings with involved stakeholders and data stewards are planned and strategies for dissemination of the results will be outlined in collaboration with knowledge users, including PopData BC, Perinatal Services BC, Metro Vancouver, Health Canada, the British Columbia Centre for Disease Control and knowledge transfer members of the Canadian Urban Environmental Health Research Consortium. ${ }^{117}$ This process will be iterated with regularly planned dissemination meetings and seminars/webinars. The aim is to disseminate the results of the project to provide data linkages and methodological input to future studies and to influence public health policies and evidence-based urban planning.

\section{CONCLUSION}

Many studies on environmental exposures, especially on $\mathrm{NE}$, have focused on adult populations, but less is known about their influence on children. By investigating the links between several modifiable environmental exposures and early childhood development, Born to be Wise will provide new evidence about how the environment affects health in childhood with subsequent impacts across the life course. The project addresses four major gaps in current knowledge: (1) the effects of noise and TRAP on various dimensions of childhood development; (2) the influence of early life (including prenatal) exposure to neighbourhood NE and the possible moderating effects of NE on harmful exposures; (3) the effect of these exposures on children of poor SES, and whether their early development can be particularly enhanced through access to NE; and (4) critical time windows and differences depending on the length of exposures for the influence of environmental exposures on early development.

Born to be Wise is relevant to a key set of contemporary challenges related to rapidly changing living environments and harmful exposures that may influence early childhood development. In many areas, these exposures are ubiquitous, thus affecting large populations with the potential for major impacts on population health. Results from the project will provide empirical evidence on the impact of environmental exposures on early development and may ultimately inform effective policies and interventions to support healthy urban planning for vulnerable populations, particularly children in socioeconomically deprived areas.

\section{Author affiliations}

${ }^{1}$ The School of Population and Public Health, The University of British Columbia, Vancouver, British Columbia, Canada

${ }^{2}$ The Department of Forest and Conservation Sciences, The University of British Columbia, Vancouver, British Columbia, Canada

${ }^{3} \mathrm{HC}$-SC, Health Canada, Ottawa, Ontario, Canada

${ }^{4}$ Department of Statistics, University of California, Berkeley, California, USA

${ }^{5}$ Fielding School of Public Health, University of California, Los Angeles, California, USA

Acknowledgements The authors would like to thank Josephine Clark and others at Metro Vancouver for their valuable guidance and input and for sharing their land cover data, used for creating the map in Figure 1.

Contributors MvdB drafted this manuscript on the basis of a grant proposal that was devised and written by her, MB, RB, HWD, MG, MJ, TO, HS and JGS. All of the authors contributed to the introduction and aims sections, providing input on existing knowledge, study design and falsifiable hypotheses (specifically MvdB, MG and T0 on socioeconomically related health inequalities, the Early Development Instrument and developmental disorders; MB, RB, HWD, MJ, HS and JGS on harmful environmental exposures, exposure metrics and analytical tools; and MvdB, ZD, IJ, MJ, LN and ER on natural environment metrics and analytical tools). IJ drafted the primary data and preliminary analysis section and developed the map, and ER developed the NSI and corresponding text. The conceptual model was developed by MvdB, MG, MJ and JGS. The methods and analytical section, in which the conception and design of aspects of the work for which the respective authors are responsible in the Born to be Wise project are described, was developed with specific input from MvdB, MB, RB, HWD, MG, MJ, LN, HS and JGS. All coauthors contributed to the writing of the implementation and conclusion sections. MvdB subsequently prepared a final version of the manuscript based on coauthor contributions. All authors then read the final version, approved it for submission for publication and agreed to be accountable for all aspects of the work.

Funding This work is supported by the Canadian Institutes of Health Research, reference number 156152

Competing interests None declared.

Patient consent Not required.

Ethics approval The University of British Columbia, Behavioural Research Ethics Board.

Provenance and peer review Not commissioned; peer reviewed for ethical and funding approval prior to submission.

Open access This is an open access article distributed in accordance with the Creative Commons Attribution Non Commercial (CC BY-NC 4.0) license, which permits others to distribute, remix, adapt, build upon this work non-commercially, and license their derivative works on different terms, provided the original work is properly cited, appropriate credit is given, any changes made indicated, and the use is non-commercial. See: http://creativecommons.org/licenses/by-nc/4.0/.

\section{REFERENCES}

1 Thomas EM. Readiness to learn at school among five-year-old children in Canada. Children and youth research paper series. Statistics Canada, Ottawa.: Minister of Industry, 2006.

2 Jolly R. Early childhood development: the global challenge. Lancet 2007;369:8-9.

3 Lake A. Early childhood development-global action is overdue. The Lancet 2011;378:1277-8.

$4 \mathrm{ClHI}$, Canadian Institute for Health Information. Children vulnerable in areas of early development: a determinant of child health. Ottawa, ON: CIHI, 2014.

5 HELP. The early development instrument:reports and resources. http://earlylearning.ubc.ca/maps/edi/ (Accessed 1 Aug 2017).

6 Santos R, Brownell M, Ekuma O, et al. The Early Development Instrument (EDI) in Manitoba: linking socioeconomic adversity and biological vulnerability at birth to children's outcomes at age 5winnipeg. MB: Manitoba Centre for Health Policy, 2012.

7 Posen A, Siddiqi A, Hertzman C. Nurturing early childhood development in times of austerity in BC: Canadian Centre for Policy Alternatives, BC Office, 2015. 
8 Brownell MD, Ekuma O, Nickel NC, et al. A population-based analysis of factors that predict early language and cognitive development. Early Childhood Research Quarterly 2016;35:6-18.

9 Mandy W, Lai MC. Annual Research Review: The role of the environment in the developmental psychopathology of autism spectrum condition. J Child Psychol Psychiatry 2016;57:271-92.

10 Suades-González E, Gascon M, Guxens M, et al. Air pollution and neuropsychological development: a review of the latest evidence. Endocrinology 2015;156:3473-82.

11 Grandjean P, Landrigan PJ. Neurobehavioural effects of developmental toxicity. The Lancet Neurol 2014;13:330-8.

12 Abbasi J. CAll to action on neurotoxin exposure in pregnant women and children. JAMA 2016.

13 Dadvand P, Nieuwenhuijsen MJ, Esnaola M, et al. Green spaces and cognitive development in primary schoolchildren. Proc Natl Acad Sci U S A 2015;112:7937-42.

14 Statistics Canada. StatCan, Census of Population, 2016Municipalities in Canada with the largest and fastest-growing populations between 2011 and 2016 Catalogue no. 98-200X2016001: Statistics Canada, 2017.

15 Mincey SK, Schmitt-Harsh M, Thurau R. Zoning, land use, and urban tree canopy cover: the importance of scale. Urban Forestry \& Urban Greening 2013;12:191-9.

16 Toronto Public Health. The walkable city: neighbourhood design and preferences, travel choices and health. 2012. Toronto Public Health, 2012.

17 Dupras J, Alam M. Urban sprawl and ecosystem services: a half century perspective in the montreal area (Quebec, Canada). Journal of Environmental Policy \& Planning 2015;17:180-200.

18 City_of_Vancouver. urban forest strategy. 2014.

19 Louv R. Leave no child inside. Orion Magazine 2007;57.

20 Louv RHJ. Last child in the woods: saving our children from nature-deficit disorder. Chapel Hill, North Carolina, United States of America: Algonquin Books of Chapel Hill, 2005.

21 Radesky JS, Christakis DA. Increased screen time: implications for early childhood development and behavior. Pediatr Clin North Am 2016:63:827-39.

22 Giedd JN. The digital revolution and adolescent brain evolution. $J$ Adolesc Health 2012:51:101-5.

23 Uhls YT, Michikyan M, Morris J, et al. Five days at outdoor education camp without screens improves preteen skills with nonverbal emotion cues. Computers in Human Behavior 2014;39:387-92.

24 Mårtensson $\mathrm{F}$, Boldemann $\mathrm{C}$, Blennow $\mathrm{M}$, et al. Attention promoting outdoor environment for children-part of a salutogenic concept. Health \& Place 2009;15:1149-57.

25 Keil KP, Lein PJ. DNA methylation: a mechanism linking environmental chemical exposures to risk of autism spectrum disorders? Environ Epigenet 2016;2:dvv012.

26 Basagaña X, Esnaola M, Rivas I, et al. Neurodevelopmental deceleration by urban fine particles from different emission sources: a longitudinal observational study. Environ Health Perspect 2016;124:1630-6.

27 Freire C, Ramos R, Puertas R, et al. Association of traffic-related air pollution with cognitive development in children. $J$ Epidemiol Community Health 2010;64:223-8.

28 Lertxundi A, Baccini M, Lertxundi N, et al. Exposure to fine particle matter, nitrogen dioxide and benzene during pregnancy and cognitive and psychomotor developments in children at 15 months of age. Environ Int 2015;80:33-40.

29 Porta D, Narduzzi S, Badaloni C, et al. Air pollution and cognitive development at age 7 in a prospective Italian Birth Cohort. Epidemiology 2016;27:228-36.

30 Clark C, Stansfeld SA. The effect of transportation noise on health and cognitive development: A review of recent evidence. Int $\mathrm{J}$ Comp Psychol 2007;20:145-58.

31 Evans GW, Hygge S. Noise and cognitive performance in children and adults, in noise and its effects, 2007:549-66.

32 Stansfeld SA, Berglund B, Clark C, et al. Aircraft and road traffic noise and children's cognition and health: a cross-national study. Lancet 2005;365:1942-9.

33 van Kamp I, Davies H. Noise and health in vulnerable groups: a review. Noise and Health 2013;15:153-9.

34 Stansfeld SA, Clark C, Cameron RM, et al. Aircraft and road traffic noise exposure and children's mental health. Journal of Environmental Psychology 2009;29:203-7.

35 Stansfeld SA, Haines MM, Brentall S, et al. West London schools study: aircraft noise at school and child performance and health. Final report. London: Department of the Environment and Transport, 2000.
36 Gluckman PD, Cutfield W, Hofman P, et al. The fetal, neonatal, and infant environments-the long-term consequences for disease risk. Early Hum Dev 2005;81:51-9.

37 Gluckman PD, Hanson MA, Cooper C, et al. Effect of in utero and early-life conditions on adult health and disease. N Engl J Med 2008;359:61-73.

38 Brauer M, Lencar C, Tamburic L, et al. A cohort study of trafficrelated air pollution impacts on birth outcomes. Environ Health Perspect 2008;116:680-6.

39 Dadvand P, Parker J, Bell ML, et al. Maternal exposure to particulate air pollution and term birth weight: a multi-country evaluation of effect and heterogeneity. Environ Health Perspect 2013;121:267-373

40 Calderón-Garcidueñas L, Engle R, Mora-Tiscareño A, et al. Exposure to severe urban air pollution influences cognitive outcomes, brain volume and systemic inflammation in clinically healthy children. Brain Cogn 2011;77:345-55.

41 Arroyo V, Díaz J, Ortiz C, et al. Short term effect of air pollution, noise and heat waves on preterm births in Madrid (Spain). Environ Res 2016:145:162-8.

42 Selander J, Albin M, Rosenhall U, et al. Maternal occupational exposure to noise during pregnancy and hearing dysfunction in children: A nationwide prospective cohort study in Sweden Environmental Health Perspectives 2016;124:855-60.

43 Gehring U, Tamburic L, Sbihi H, et al. Impact of noise and air pollution on pregnancy outcomes. Epidemiology 2014;25:351-8.

44 Astell-Burt T, Feng X, Mavoa S, et al. Do low-income neighbourhoods have the least green space? A cross-sectional study of Australia's most populous cities. BMC Public Health 2014:14:292.

45 Braubach M, Fairburn J. Social inequities in environmental risks associated with housing and residential location-a review of evidence. Eur J Public Health 2010;20:36-42.

46 Briggs D, Abellan JJ, Fecht D. Environmental inequity in England: small area associations between socio-economic status and environmental pollution. Soc Sci Med 1982, 2008;67.

47 Pearce JR, Richardson EA, Mitchell RJ, et al. Environmental justice and health: The implications of the socio-spatial distribution of multiple environmental deprivation for health inequalities in the United Kingdom. Transactions of the Institute of British Geographers 2010;35:522-39.

48 Martuzzi M, Mitis F, Forastiere F. Inequalities, inequities, environmental justice in waste management and health. The European Journal of Public Health 2010;20:21-6.

49 Markevych I, Tiesler CM, Fuertes E, et al. Access to urban green spaces and behavioural problems in children: Results from the GINIplus and LISAplus studies. Environ Int 2014;71:29-35.

50 Amoly E, Dadvand P, Forns J, et al. Green and blue spaces and behavioral development in Barcelona schoolchildren: the BREATHE project. Environ Health Perspect 2014;122:1351-8.

51 Taylor AF, Kuo FEM. Could exposure to everyday green spaces help treat ADHD? Evidence from children's play settings. Applied Psychology: Health and Well-Being 2011;3:281-303.

52 van den Berg $A E$, van den Berg CG. A comparison of children with ADHD in a natural and built setting. Child Care Health Dev 2011;37:430-9.

53 Kuo FE, Taylor AF. A potential natural treatment for attention-deficit/ hyperactivity disorder: evidence from a national study. Am J Public Health 2004;94:1580-6.

54 Taylor AF, Kuo FE. Children with attention deficits concentrate better after walk in the park. J Atten Disord 2009;12:402-9.

55 Taylor AF, Kuo FE, Sullivan WC. Coping with ADD The surprising connection to green play settings. Environment and Behavior 2001;33:54-77.

56 Taylor AF, Kuo FE, Sullivan WC. Views of nature and self-discipline: evidence from inner city children. $J$ of Environmental Psychology 2002;22(1-2):49-63.

57 Nowak DJ, Hirabayashi S, Bodine A, et al. Modeled PM2.5 removal by trees in ten U.S. cities and associated health effects. Environ Pollut 2013;178:395-402.

58 Selmi W, Weber $\mathrm{C}$, Rivière $\mathrm{E}$, et al. Air pollution removal by trees in public green spaces in Strasbourg city, France. Urban For Urban Green 2016;17:192-201.

59 Buccolieri R, Salim SM, Leo LS, et al. Analysis of local scale treeatmosphere interaction on pollutant concentration in idealized street canyons and application to a real urban junction. Atmospheric Environment 2011;45:1702-13.

60 Abhijith KV, Kumar P, Gallagher J, et al. Air pollution abatement performances of green infrastructure in open road and built-up street canyon environments - A review. Atmospheric Environment 2017:162:71-86. 
61 Janhäll S. Review on urban vegetation and particle air pollution - Deposition and dispersion. Atmospheric Environment 2015;105:130-7.

62 Chen $\mathrm{D}$, Wang $\mathrm{X}$, Thatcher $\mathrm{M}$, et al. Urban vegetation for reducing heat related mortality. Environ Pollut 2014;192:275-84.

63 Bowler DE, Buyung-Ali L, Knight TM, et al. Urban greening to cool towns and cities: a systematic review of the empirical evidence. Landscape and Urban Planning 2010;97:147-55.

64 Shishegar $\mathrm{N}$. The impacts of green areas on mitigating urban heat Island effect. The International Journal of Environmental Sustainability 2014;9:119-30.

65 Dzhambov AM, Dimitrova DD. Urban green spaces' effectiveness as a psychological buffer for the negative health impact of noise pollution: a systematic review. Noise Health 2014;16:157-65.

66 Dzhambov AM, Dimitrova DD. Green spaces and environmental noise perception. Urban For Urban Green 2015;14:1000-8.

67 Pathak V, Tripathi BD, Mishra VK. Evaluation of anticipated performance index of some tree species for green belt development to mitigate traffic generated noise. Urban For Urban Green 2011;10:61-6.

68 Sallis J, Prochaska J, Taylor W. A review of correlates of physical activity of children and adolescents. Med Sci Sports Exerc 2000;32:963-75.

69 Sallis JF, Cerin E, Conway TL, et al. Physical activity in relation to urban environments in 14 cities worldwide: a cross-sectional study. The Lancet 2016;387:2207-17.

70 Cohen DA, Ashwood JS, Scott MM, et al. Public parks and physica activity among adolescent girls. Pediatrics 2006;118:e1381-e1389.

71 Roe J, Aspinall P. The restorative outcomes of forest school and conventional school in young people with good and poor behaviour. Urban Forestry \&amp; Urban Greening 2011;10:205-12

72 Roe JJ, Thompson CW, Aspinall PA, et al. Green space and stress: evidence from cortisol measures in deprived urban communities. Int $J$ Environ Res Public Health 2013;10:4086-103.

73 Ward Thompson C, Aspinall P, Roe J, et al. Mitigating stress and supporting health in deprived urban communities: the importance of green space and the social environment. Int J Environ Res Public Health 2016;13:440.

74 Annerstedt M, Ostergren PO, Björk J, et al. Green qualities in the neighbourhood and mental health - results from a longitudinal cohort study in Southern Sweden. BMC Public Health 2012;12:337

75 van den Bosch MA, Östergren PO, Grahn P, et al. Moving to serene nature may prevent poor mental health-results from a swedish longitudinal cohort study. Int J Environ Res Public Health 2015:12:7974-89.

76 Bratman GN, Daily GC, Levy BJ, et al. The benefits of nature experience: Improved affect and cognition. Landscape and Urban Planning 2015;138:41-50.

77 Bratman GN, Hamilton JP, Hahn KS, et al. Nature experience reduces rumination and subgenual prefrontal cortex activation. Proc Natl Acad Sci U S A 2015;112:8567-72

78 Zhang JW, Howell RT, lyer R. Engagement with natural beauty moderates the positive relation between connectedness with nature and psychological well-being. J Environ Psychol 2014;38.

79 Zhang JW, Piff PK, lyer R, et al. An occasion for unselfing: Beautifu nature leads to prosociality. Journal of Environmental Psychology 2014;37:61-72

80 Zelenski JM, Dopko RL, Capaldi CA. Cooperation is in our nature: nature exposure may promote cooperative and environmentally sustainable behavior. Journal of Environmental Psychology 2015;42:24-31.

81 Zelenski JM, Nisbet EK. Happiness and feeling connected: the distinct role of nature relatedness. Environ Behav 2012;46.

82 Rook GA. Regulation of the immune system by biodiversity from the natural environment: An ecosystem service essential to health. Proceedings of the National Academy of Sciences 2013;110:18360-7.

83 Rook GA, Lowry CA, Raison CL. Hygiene and other early childhood influences on the subsequent function of the immune system. Brain Res 2015;1617:47-62.

84 Pakarinen J, Hyvärinen A, Salkinoja-Salonen M, et al. Predominance of Gram-positive bacteria in house dust in the low-allergy risk Russian Karelia. Environ Microbiol 2008;10:3317-25.

85 Mitchell R, Popham F. Effect of exposure to natural environment on health inequalities: an observational population study. The Lancet 2008;372:1655-60.

86 Mitchell RJ, Richardson EA, Shortt NK, et al. Neighborhood environments and socioeconomic inequalities in mental well-being. Am J Prev Med 2015;49:80-4.
87 Janus M, Offord DR. Development and psychometric properties of the Early Development Instrument (EDI): a measure of children's school readiness. Can J Behav Sci 2007;39:1-22.

88 Forget-Dubois N, Lemelin J-P, Boivin M, et al. Predicting Early School Achievement With the EDI: a longitudinal population-based study. Early Education and Development 2007;18:405-26.

89 Lloyd JE, Li L, Hertzman C. Early experiences matter: lasting effect of concentrated disadvantage on children's language and cognitive outcomes. Health Place 2010;16:371-80.

90 Brinkman SA, Silburn S, Lawrence D, et al. Investigating the validity of the Australian early development index. Early Education and Development 2007;18:427-51.

91 Janus M, Brinkman SA, Duku EK. Validity and psychometric properties of the early development instrument in canada, australia, united states, and jamaica. Social Indicators Research 2011;103:283-97.

92 Forer B, Zumbo BD. Validation of multilevel constructs: validation methods and Empirical Findings for the EDI. Social Indicators Research 2011;103:231-65.

93 Muhajarine N, Puchala C, Janus M. Does the EDI Equivalently Measure Facets of School readiness for aboriginal and non-aboriginal children? Social Indicators Research 2011;103:299-314.

94 Webb S, Janus M, Duku E, et al. Neighbourhood socioeconomic status indices and early childhood development. SSM Popul Health 2017;3:48-56.

95 Wentz E, Anderson S, Fragkias M, et al. Supporting global environmental change research: a review of trends and knowledge gaps in urban remote sensing. Remote Sensing 2014;6:3879-905.

96 Kriegler FJMWANRF, Richardson W. Preprocessing transformations and their effects on multispectral Recognition. Proceedings of the Sixth International Symposium on Remote Sensing of Environment 1969:97-131.

97 Annerstedt van den Bosch M, Mudu P, Uscila V, et al. Development of an urban green space indicator and the public health rationale. Scand J Public Health 2016;44:159-67.

98 Williams D. New approaches for understanding urban greenspace using ecosystem services concepts and high spatial resolution mapping. Vancouver, Canada: The University of British Columbia, 2018.

99 Edwards N, Hooper P, Trapp GSA, et al. Development of a Public Open Space Desktop Auditing Tool (POSDAT): a remote sensing approach. Applied Geography 2013;38:22-30.

100 Rugel EJ, Henderson SB, Carpiano RM, et al. Beyond the Normalized Difference Vegetation Index (NDVI): developing a natural space index for population-level health research. Environ Res 2017;159(Supplement C):474-83.

101 Yang J, Zhao L, McBride J, et al. Can you see green? Assessing the visibility of urban forests in cities. Landscape and Urban Planning 2009;91:97-104.

102 Li X, Zhang C, Li W, et al. Assessing street-level urban greenery using Google Street View and a modified green view index. Urban Forestry \& Urban Greening 2015;14:675-85.

103 Abernethy RC, Allen RW, McKendry IG, et al. A land use regression model for ultrafine particles in Vancouver, Canada. Environ Sci Technol 2013;47:5217-25.

104 Henderson SB, Beckerman B, Jerrett M, et al. Application of land use regression to estimate long-term concentrations of trafficrelated nitrogen oxides and fine particulate matter. Environ $\mathrm{Sci}$ Technol 2007;41:2422-8.

105 Gan WQ, McLean K, Brauer M, et al. Modeling population exposure to community noise and air pollution in a large metropolitan area. Environ Res 2012;116:11-16.

106 Wang $\mathrm{R}$, Henderson SB, Sbihi $\mathrm{H}$, et al. Temporal stability of land use regression models for traffic-related air pollution. Atmos Environ 2013;64:312-9.

107 Dell SD, Jerrett M, Beckerman B, et al. Presence of other allergic disease modifies the effect of early childhood trafficrelated air pollution exposure on asthma prevalence. Environ Int 2014;65:83-92.

108 Brokamp C, LeMasters GK, Ryan PH. Residential mobility impacts exposure assessment and community socioeconomic characteristics in longitudinal epidemiology studies. J Expo Sci Environ Epidemiol 2016;26:428-34.

109 Strosnider H, Zhou Y, Balluz L, et al. Engaging academia to advance the science and practice of environmental public health tracking. Environ Res 2014;134:474-81.

110 Ortega Hinojosa AM, Davies MM, Jarjour S, et al. Developing smallarea predictions for smoking and obesity prevalence in the United States for use in Environmental Public Health Tracking. Environ Res 2014:134:435-52. 
111 Hughes E. Cox-Poisson Program (GAMEPHIT) Geographic and Multi-level Models for Environmental Public Health Indicators and Tracking. 2013.

112 Gan WQ, Tamburic L, Davies HW, et al. Changes in residential proximity to road traffic and the risk of death from coronary heart disease. Epidemiology 2010;21:642-9.

113 Preacher KJ, Hayes AF. SPSS and SAS procedures for estimating indirect effects in simple mediation models. Behav Res Methods Instrum Comput 2004;36:717-31.

114 Hayes AF, Preacher KJ. Quantifying and Testing Indirect Effects in Simple Mediation Models When the Constituent Paths Are Nonlinear. Multivariate Behav Res 2010;45:627-60.

115 Preacher KJ, Rucker DD, Hayes AF. Addressing Moderated Mediation Hypotheses: Theory, Methods, and Prescriptions. Multivariate Behav Res 2007;42:185-227.
116 Guhn M, Gadermann AM, Almas A, et al. Associations of teacherrated social, emotional, and cognitive development in kindergarten to self-reported wellbeing, peer relations, and academic test scores in middle childhood. Early Child Res Q 2016;35:76-84.

117 Brook JR, Setton EM, Seed E, et al. The Canadian Urban Environmental Health Research Consortium - a protocol for building a national environmental exposure data platform for integrated analyses of urban form and health. BMC Public Health 2018;18:114.

118 Statistics_Canada. StatCan SC, Postal Code Conversion File, November 2014 Postal Codes. Canada: Statistics Canada (Statcan), 2015.

119 Williams DAR, Matasci G, Coops NC, et al. Object-based urban landcover mapping methodology using high spatial resolution imagery and airborne laser scanning. J Appl Remote Sens 2018;12:1 